\title{
Un experiment transcultural ${ }^{\dagger}$
}

\author{
Lucian Chișu* \\ Institutul de Istorie și Teorie Literară „G. Călinescu”, Calea 13 Septembrie 13, 050711 București, România \\ Muzeul Național al Literaturii Române, Piața Presei Libere 1, Corp A4, Etaj 2, 013701 București, România
}

\section{Despre articol}

Istoric:

Primit 21 iunie 2016

Acceptat 15 iulie 2016

Publicat 1 august 2016

Cuvinte-cheie:

literatură

identitate

mentalitate

multiculturalism

\begin{abstract}
Rezumat
Proiectul de a crea o arhivă grafică și de caricaturi (alcătuită din portrete ale marilor scriitori români din diferite perioade literare), dus la capăt cu sprijinul artiștilor talentați din toată lumea, a dobîndit o nouă dimensiune literar-istorică, datorită uriaşului interes stîrnit. După o selecție geografică și calitativă, au fost publicate două ediții tipărite: una în română, cealaltă în engleză, fiecare dintre ele cuprinzînd 3600 de imagini aparținînd artiștilor de pe toate continentele (112 țări). Această carte fără precedent, numită $O$ istorie a literaturii române desenată de marii graficieni ai lumii (Editura Muzeului Literaturii Române, 2009) prezintă aspecte transculturale demne de toată atenția istoricilor literari, a biografilor, a artiștilor cuvîntului și ai imaginii (scriitori, graficieni, caricaturiști), dar, datorită neobișnuitei forme de dialog deschis, și a specialiștilor în studii culturale (antropologie, semiotică, mentalitate).
\end{abstract}

1. Cu toții trăim această realitate incontestabilă: globalizarea / mondializarea. Efectele manifestării fenomenului în sferele economiei, socialului și ale culturii, au generat numeroase dispute în rîndul specialiștilor preocupați de provocările societăţii contemporane ${ }^{1}$. Mai mult ca oricînd, astăzi, datorită forței gravitaționale pe care cunoașterea o exercită, nemijlocit și necontrolat, prin recent definita Societate Informaţională a Cunoașterii $(\mathrm{SIC})^{2}$ asupra a miliarde de indivizi, civilizația umană se reconfigurează continuu asemenea unei mișcări browniene, la scară planetară ${ }^{3}$.

Între fenomenul cultural și așteptările societății ${ }^{4}$, schimbările produse de noile tehnologii au bulversat literalmente raporturile și proporţiile creîndu-se un decalaj imens manifestat prin predominanța efectelor globalizării asupra structurilor tradiției. Consecința acestei presiuni exercitate prin vectorul economic a condus la erodarea continuă a aspectelor identitare, exprimate în coduri lingvistice naționale și conservate prin intermediul unor seturi de reguli etice, morale specifice evoluțiilor respectivelor națiuni. Dacă fiecare dintre limbile culte și-a prezervat structura gramaticală, nu același lucru se poate spune despre lexicul acestora, al cărui nucleu (vocabular esențial) a fost invadat, în era SIC, de termenii unici descriptori ai tehnologiilor și instrumentelor comunicării, astăzi la îndemîna a miliarde de utilizatori. Observația unui celebru lingvist francez (A. Meillet) — anume că în etimologia cuvintelor se reflectă și istoria civilizației vedește caracterul premonițial pentru această fază „terminală”, cînd puternica tendință de destructurare a

\footnotetext{
†O variantă a textului a apărut în „Caiete critice”, nr. 6 (296), 2012, p. 39-49.

*Adresă de corespondență: lucianchisu@gmail.com.

${ }^{1}$ Huntington (1998). În acest sens, studii elaborate în Canada, SUA, Australia, Noua Zeelandă și, după căderea sistemului politic comunist, în Europa, au constituit placa turnantă a domeniului, cu terminologii și distincții de la o zona la alta, de la o cultură la alta.

${ }^{2}$ Societatea în care informația este recunoscută drept (re)sursă principală, iar producerea și consumul de informație reprezintă cel mai important tip de activitate.

${ }^{3}$ Este de ajuns să amintim faptul că topul celor mai frecvente profesii este ocupat de unele absolut noi, inexistente în urmă cu numai cinci ani.

${ }^{4}$ Simmel (1987) susținea că această criză este „rezultatul conflictului dintre procesele vieții, care nu știe ce-i răgazul, și formele ei de exprimare culturală, care nu știu ce-i schimbarea”.

${ }^{5}$ „La langue étant de tous les faites humaines le plus manifestent social—car ni langue n’est imaginable sans la société, ni la société des hommes sans langue-les conditions sociales dominent le langage”, în „Bulletin de la Société de Linguistique de Paris", XXV (1924-1925), fasc. 2, p. 2, apud Graur \& Wald (1977).
} 
Lucian Chișu

vechilor valori și tradiții identitare are loc în urma formării unui autentic mainstream comunicațional. Din cauza efectelor globalizării însuși termenul național a fost translat în sfera de semnificații a altui concept, identitar, parțial sinonimic, ceea ce a permis, de la caz la caz, de la națiune la națiune, eludarea rigorilor de tip axiologic care acționează în conformitate cu tradiția. Însăși tradiției i-au fost anexate componente cu un autentic rol consumerist. Studiul noilor forme socio-culturale (Baber, 2012), designate cu ajutorul unor prefixe ca: inter-, multi-, trans-, ori cu substantive precum cosmopolitism și bybrid care, la rîndul lor, formează compuși lingvistici cu termenul cultură / cultural a determinat, pe lîngă o relaxare de natură conceptuală, apariția noilor abordări interdisciplinare Astfel de studii și cercetări deschid noi orizonturi, desigur interdisciplinare, vizînd multiple contexte nebănuite, dar pline de informații prețioase ${ }^{6}$.

2. În consonanță cu cele mai înainte afirmate, articolul de față se referă la șansele oferite culturilor mici ca întindere geografică (în cazul nostru, literatura română) de a se face cunoscute (vizibile) în dialogul contemporan multicultural. Semnalăm de la bun început dezavantajul limbii române, anume acela de a fi activă pe o arie lingvistică de mici dimensiuni, comparativ cu idiomurile de mare răspîndire ori de circulație internațională, cum este cazul limbilor engleză, franceză, spaniolă, chineză. De aceea, am apelat la un experiment în care legile ,independente” ale multiculturalismului, dirijate de factorii sociali ori de tendințele naturale de impact și evoluție economică, au fost reconfigurate conjunctural.

Între cei doi termeni, (multi- și / ori transculturalism), optăm pentru transculturalism (Cuccioletta, 2001-2002 $)^{7}$, așa cum acesta s-a manifestat în cadrul provocării experimentului. Situația reprezintă un aspect insolit față de cercetările consacrate comunicării interculturale ${ }^{8}$, optînd nu pentru disfuncții, ci pentru o formulă de optimizare, aspect sub care termenul transculturalism ar putea fi bine suplinit de sintagma cultură hybridă în accepțiunea dată de Ryszard Kluszczynski ${ }^{9}$, cu care sîntem numai parțial de acord.

Experimentul s-a concretizat în realizarea unei antologii (Ioniță, 2009) și a constat în cerința adresată „comunității” graficienilor de pretutindeni (din lume) de a-și exprima, în maniera specifică profesiei lor, un punct de vedere sintetic și cultural asupra celor mai importanți dintre scriitorii români din toate timpurile. Aceștia (repondenții) trebuiau să se adapteze la noul context, inter- și multicultural, sub următoarele incidențe: (a) invitarea la dialog prin intermediul unui subiect necunoscut (străin); (b) obținerea de informații și, ulterior, (c) realizarea, grație acumulărilor de cunoaștere / informare, a ceea ce am numit dialogul transcultural, cu (d) variile sale forme de interpretare. Intra în calcul relativizarea ,propriului cîmp cultural” (Bourdieu, 1993, p. 41), care semnifica interogarea și negocierea fondului comun de cunoaștere, precum și capacitatea de nou realizată. O primă constatare se referă la obținerea informațiilor și, apoi, la ordonarea lor în ceea ce s-a numit-oarecum impropriu, dar îndeajuns de persuasiv—, o panoramă a literaturii române. Edificarea a fost posibilă atît pe criteriile valorice, cît și pe cele istorico-literare (diacronice). Explicația realizării acestui tip de bună practică se datorează capacitatății breslei de a „filtra”

\footnotetext{
${ }^{6}$ Diversitatea lor poate fi semnalată la tot pasul. De pildă, teza de doctorat cu titlul Food as a Transcultural Metaphor (Food Imagery and Ethnocultural Identities in Contemporary Multicultural Women Writing in Canada) de Katarina Hinnerova, în cadrul Faculty of Art. Departament of English and Amercian Studies, Masaryk University, Brno (2007).

${ }^{7}$ Transculturalismul este definit ca ,seeing oneself in the other".

${ }^{8}$ Cercetările și studiile de acest tip sînt, în imensa lor majoritate, consacrate studiului stărilor de fapte existente (concrete) și nu urmăresc, precum în acest caz, ... provocarea lor. Pe de altă parte, primim cu un sentiment de insatisfacție, faptul că, de pildă, multe dintre descoperirile revelatorii din cadrul comunicării au avut drept consecință studii efectuate asupra persoanelor cu dizabilitați în exprimare / comunicare.

9 "One of the most important factors of the hybrid condition of contemporary arts is the complex relationship between arts and sciences and technologies. Such relations develop a new concept of third culture, not based-as in the theory of John Brockman-on the conflict between traditional humanistic values and scientific systems, but on the interactions between them. (...) Hybrid cultures are phenomena of essential connections in the present. They emerge from diverse and complex influences. Hybrid cultures are mergers that combine past and present, local and translocal, space and place and technoscape. Hybridity is expressed in various cultural contexts and in the in between spaces of arts, media, science and technology. Under the sign of the digital and the global, hybridity connotes a cultural manifestation of multiple appearances, as in cyberspace and multiple selves" (ISEA 2011 Istanbul, The 17th International Symposium on Electronic Art, 14-21 sept., 2011).
} 
rapid și eficient informația. Ca să se impună în profesiunea pe care și-au ales-o, acești graficieni, indiferent de națiune sau localizare, au în comun calități reale cum sînt inteligența, curiozitatea, fantezia, puterea de sinteză, rapiditatea, fiecare dintre ele servite, nu în ultimul rînd, de propriul talent artistic.

3. Celelalte situații interpretative decurg din răspunsurile primite și redate în formatul unor volume totalizînd 450 de pagini, 1500 și 300 de pagini în cuprinsul cărora se regăsesc cîteva mii de imagini. Dintre concluziile care se detașează, atrag atenția:

A. Colaboratorii acestui experiment transcultural reprezintă 122 de națiuni, prezente în ordine alfabetică și răspîndite pe întreg globul terestru, permiţîndu-ne să consemnăm aspectul său mondializant, multiși transcultural. Trebuie observat că, în absența tehnologiilor comunicării, acest deziderat ar fi fost de neatins în ceea ce privește aria sa de răspîndire și efectul de simultanietate al comunicării. Rezumarea de față îi conferă globalizării un nou statut: cel axiomatic.

$B$. Aceste întreite apariții și mai ales Caragiale - un omagiu planetar au dimensiuni uriașe vorbind de la sine despre importanța (valoarea) personalităților vizate. Deoarece numărul imaginilor existente în cele trei volume însumînd 1500 de pagini se ridică la cîteva mii de viziuni portretistice, stăruim prioritar asupra celor consacrate marelui dramaturg în anul centenarului morții sale. Am folosit și alte exemplificări, extrem de puține, din $O$ istorie a literaturii române în viziunea marilor graficieni ai lumii, aparținînd, ca idee, aceluiași inițiator, Nicolae Ioniță (Ioniță, 2009). Cum s-a arătat mai sus, informațiile oferite de repondenți au, ele însele, o complexitate care se lasă lesne supusă interpretărilor. Acestea pot fi desprinse în mai multe tipuri de informații:

a) Unele dintre imagini sînt rezultatul remarcabilei capacităţi inutitive și sintetizatoare a desenatorilor (pălărie / ochelari / mustață), aspect sub care I.L. Caragiale este recompus din numai cîteva detalii / liniii ${ }^{10}$ care dezvăluie valențe semiotice (Figura 1).

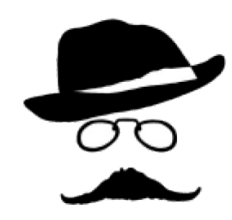

[G.

Gepp and Maia Brazilia

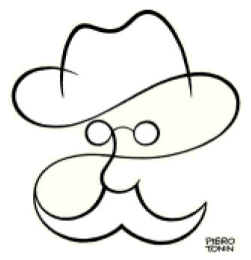

Piero Tonin Italia

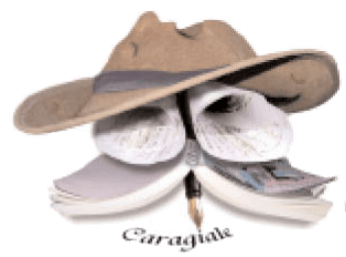

Fil Foutisse

Franța



Quel

Spania

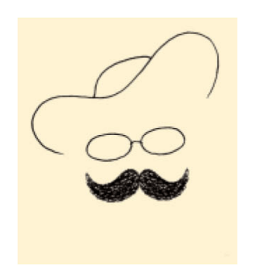

Reiner Schwalme

Germania

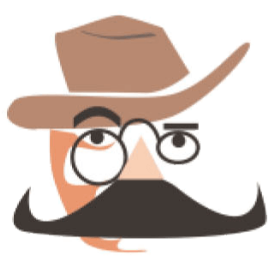

Mosquera Beceiro Spania



Gokul T G India

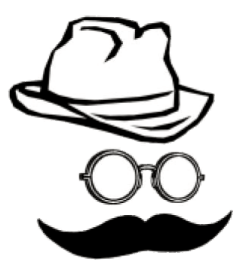

T. Sittipongsutti Thailanda

Figura 1

b) Iconografia devansează toate celelalte tipuri de informație, fapt explicabil prin (profesia) autorilor, a căror modalitate de abordare, în absența textului literar-la care, se presupune, accesul a diferit de la caz la

\footnotetext{
${ }^{10}$ Ca să poată reda chipul uman, aparatul fotografic îl „reface” dintr-o mulțime de puncte (pixeli) contrastante între ele. Camera de luat vederi poate realiza aceeași figură umană folosind aproximativ 900 de linii orizontale, din fragmentarea cărora se detașează imaginea. Or, este știut că artiștii portretului desenat pot realiza aceeași performanță prin trasarea unei singure linii continue, prin intermediul căreia ies la iveală, odată cu imaginea, și trasături temperamentale.
} 
caz-s-a concretizat în reproducerea cu mijloace caricaturale, uneori ținînd aproape de fotografie, a unui portret. Dincolo de imaginea rezultată, datele culturale sînt adăugate prin serii de simboluri ale uneltelor scrisului (pană de scris, carte, toc cu peniță, mașină de scris, manuscris; v. Figura 2), coagulînd prin efigie apartenența lui I.L. Caragiale la breasla scriitorilor.

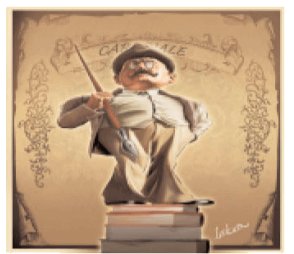

Thiago Lobo

Brazilia

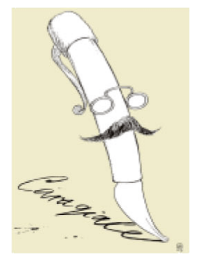

V. Sardinha

Portugalia



Tsocho Peev

Bulgaria

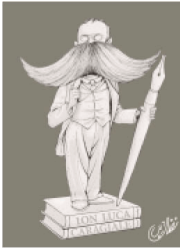

Nedal Deep

Siria



Roberto Alarcon

Guatemala

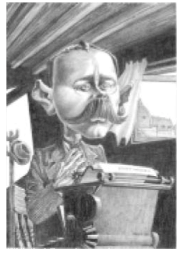

D. Gray

Marea Britanie



Doddy Iswahyudi Indonezia

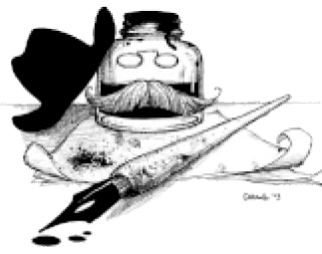

S. Carroll

Marea Britanie

Figura 2

Toate exemplificările ni se par concludente: tocul / stiloul sau chiar mașina de scris, însoțesc ori „compun” elemente care îl recompun fizionomic pe Caragiale. La fel, portretul stilizat în cele trei elemente inseparabile (pălărie, ochelari, mustață) poziționat pe fundalul unei scene de teatru, cu cortina larg deschisă. Ironistul este întruchipat în seria imaginilor de faţă şi în postura de „vînător” care, în loc de pușcă are un toc cu peniță, iar în cartușieră ține cărți în loc de gloanțe. Nu în ultimul rînd, un alt autor îi redă dramaturgului coerența simbolică apelînd la călimara de cerneală pe care sînt postate ochelarii și mustața, călimară pe care se sprijină nelipsita pălărie din fotografiile transmise posterității. Alături de ele, tocul și foaia de hîrtie se adaugă ca elemente de sens ale portretului realizat într-un grad înalt de abstractizare.

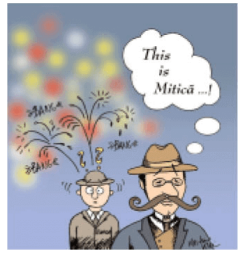

Martina Klein Germania

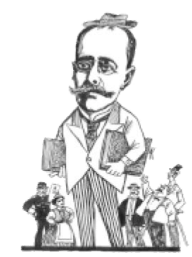

Nikolaj Kapusta Ucraina

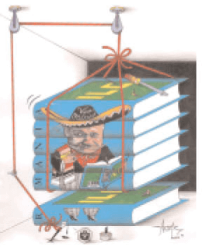

Arturo Rosas

Mexic

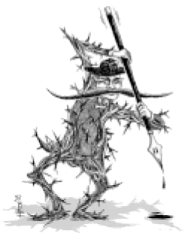

Matt Duck

Marea Britanie

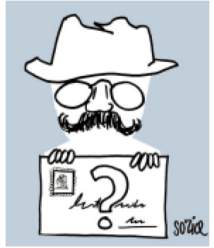

Guillermo Soria Spania

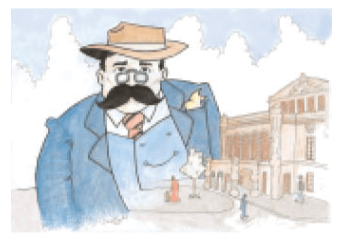

David Baillie

Marea Britanie



Hikmet Cerrah Turcia

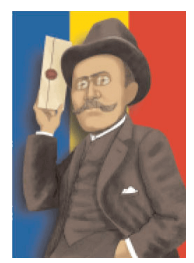

Diane Barton S.U.A.

Figura 3 
Pe de altă parte, alte serii de imagini cumulează informații referitoare la biografia scriitorului, la opera şi personajele sale sau chiar referitor la activități ori preocupări ale dramaturgului, cum a fost și aceea de de conducător de reviste.

Recunoaștem în Figura 3 trimiteri la Scrisoarea pierdută (cu străvezii aluzii la adrisantul necunoscut). În aceeași serie apare unul dintre personajele emblematice ale lumii lui Caragiale, regățeanul Mitică, tipeul ironic stîlp de cîrciumă, consumator de mici și bere, uneori fanfaron, colocvial, simpatic, mai totdeauna și pus pe glume ori gata să rîdă de ceilalți. Un moment extrem de sugestiv se regăsește în maniera contopirii publicației „Ghimpele” cu biografia scriitorului. Nu lipsite de interes sînt imaginile în care I.L. Caragiale apare înconjurat de personajele sale, ori în calitatea de director al Teatrului Naţional.

c) Foarte multe dintre desene, prezențe grafice ori caricaturi, dispun subiacent de informație istoricoliterară, uneori de amănunt, fapt care dovedește că dialogul a suscitat investigații mai ample, interpretate şi redate ca atare, prin subtilităţi (Figura 4).

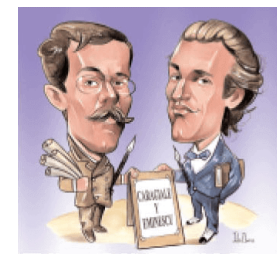

Julio Ibarra

Argentina

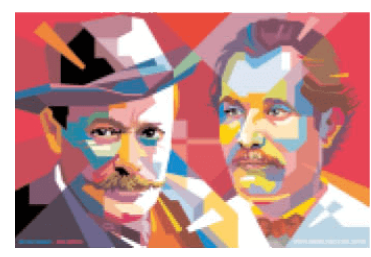

S. Priyanto

Indonezia

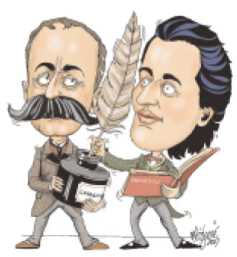

Serge Métivier

Canada

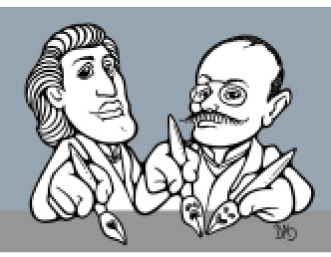

Daniel Sahade

Japonia

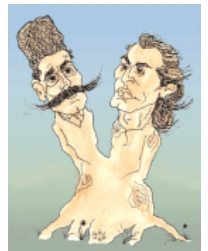

Imre Gaspar

Ungaria



K. A. Ligones Arabia

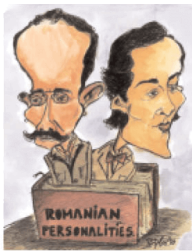

Kumar Bora India



Renato Ciavola Italia

Figura 4

De pildă, prietenia care i-a legat pe Eminescu şi Caragiale apare ades motivată mergînd pînă la reprezentarea, alături de aceștia, a Veronicăi Micle (Figura 4, ultima grafică), poeta a cărei biografie a avut implicații majore în viața lui Eminescu, dar și un episod în existența celui de-al doilea.

d) În volumul omagial atrage atenția o foarte inventivă rezolvare. Celebra zicere caragialiană „simt enorm și văd monstruos”, ia o turnură aparte (Figura 5). Tot prin diferențiere se pot desprinde: componenta națională (Figura 6), dar și referințele despre valoarea sa universală (Figura 7).

4. În ceea ce privește caracterul transcultural al acestor portretizări, ele atrag în mod special atenția (Figura 8).

Fără a depăna numeroasele exemple la care am putea face apel, invocăm numai cîteva exemple, întru totul edificatoare. În ceea ce-l privește pe I.L. Caragiale, forța de transpunere în alt orizont cultural se manifestă edificator în reprezentarea unui grafician japonez, care adaptează incisivitatea ironică a dramaturgiei lui I.L. Caragiale, reprezentîndu-l în postura unui luptător (samurai), cu toc în loc de spadă și cu multe alte detalii la vedere.

Același artist se ocupă de Eugen Ionescu apelînd la cunoscutul teatru de umbre asiatic. Pe peretele în dreptul căruia se află dramaturgul se profilează, din ,jocul” degetelor împreunate ale mîinilor, un ... rinocer (aluzie la piesa de teatru Rinocerii). La un alt autor, de această dată african, asimilarea transculturală a lui Eugen Ionescu survine prin aplicarea pe fața dramaturgului a tatuajelor totemice aparținînd unui trib, prin 


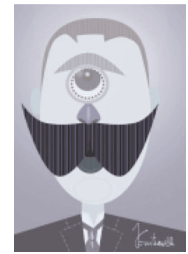

S. Martinez

Argentina

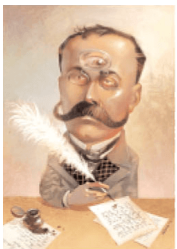

Svetlin Velinov

Bulgaria

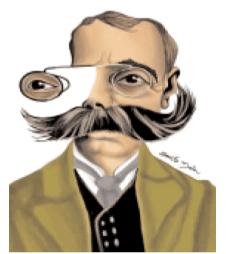

Souto Maior

Brazilia

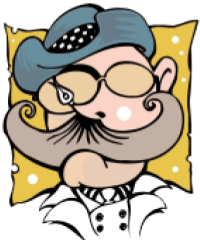

J. Briceno-Rac

Panama



Guto Camargo

Brazilia



Sevket Yalaz

Turcia

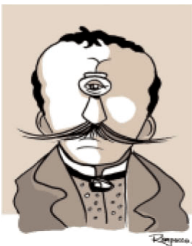

Marcelo Rampazzo

Brazilia

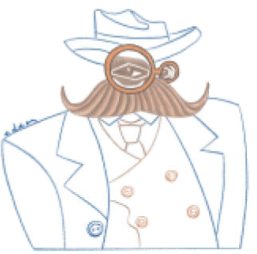

Eden

Uruguay

Figura 5

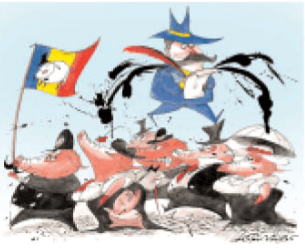

Gaston Vinas Argentina



Arafeh Kahil Iordania

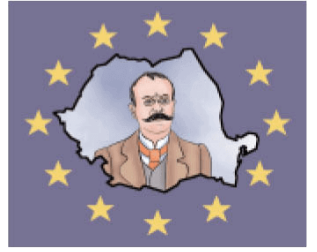

H. Al-Gayeb Babrain



F. Rasoamaharo Madagascar

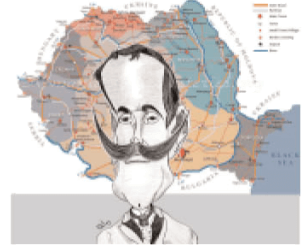

Marcelo Jorge

Brazilia



Kalifa

Trinidad Tobago

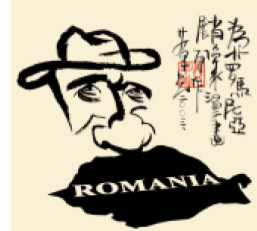

Ai Zaoxian

China

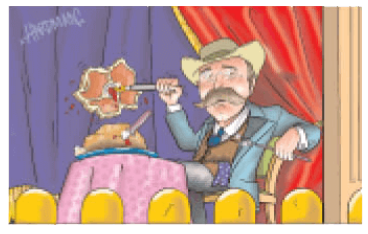

Kalifa

Trinidad Tobago

Figura 6

care se sugerează că acesta este unul de-al lor. La fel se petrec lucrurile cu Eminescu și Cioran—în viziunea unor asiatici-portretele celor doi aparținînd, în contextul dat, națiunii aparţinătoare graficianului.

5. Tot ca un efect transcultural interpretăm tendința celor mai mulți dintre autorii volumului invocat de a și-i reprezenta pe scriitorii români, și anume pe cei mai cunoscuți și a căror creație este atinsă de genialitate, în viziuni al căror mesaj este post-modern. Vedem în aceste reprezentări, nu o modă ci o cale de dialog cu lumea contemporană, dialog accesibil mai ales operelor despre care spunem, cu un cuvint devenit truism, că sînt nemuritoare. Numai astfel putem explica enorma priză de care se bucură I.L. Caragiale, de la a cărui moarte a trecut deja un secol: mesajul operei sale și-a păstrat neștirbită actualitatea putînd fi metabolizat în variante postmoderne dintre cele mai insolite (Figura 9).

6. Ca o concluzie, în întregul ei $O$ istorie literaturii române în viziunea marilor graficieni ai lumii reprezintă un efort transcultural notabil și își dezvăluie cîteva importante atribute: 


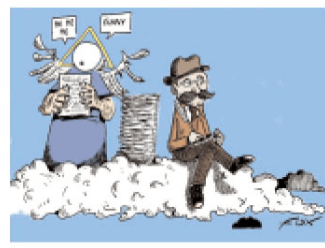

Fox

Franța

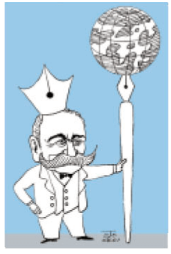

Kim Sungjoo

Coreea

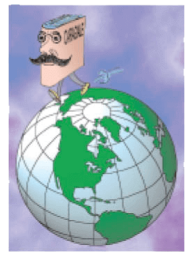

Yolette Mengual

Haiti

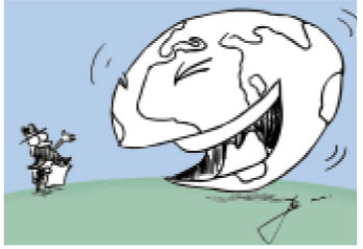

Zemgus Zaharans

Lituania

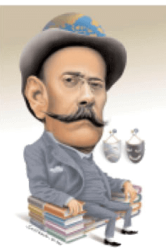

Susthanto

Indonezia

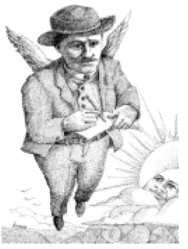

M. Imrane Coulibaly

Mali

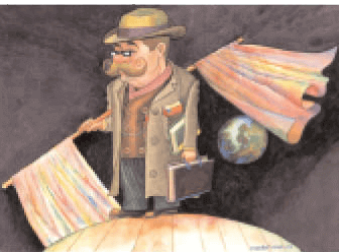

Ali Mandalawi

Irak



Shujaat Ali

Pakistan

Figura 7



N. Sooben Africa de Sud

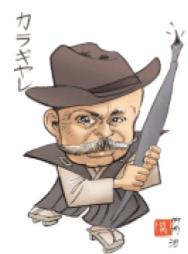

Edson O. Takeuti Japonia

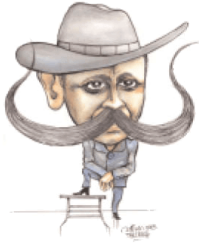

N. Mpangala

Tanzania

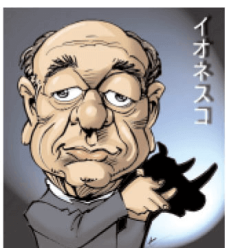

Edson O. Takeuti

Japonia

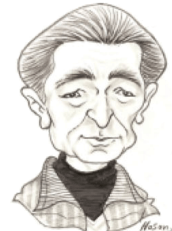

Hasan Said Egipt

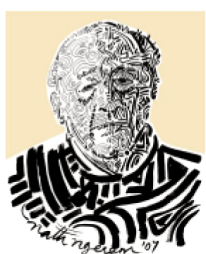

Nath Ngerem

Nigeria

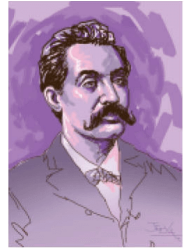

V. Jeevananthan India

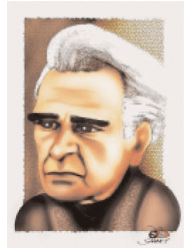

Demir Yalcin

Turcia

Figura 8

A. Marii scriitori pot fi buni ambasadori ai culturii pe care o reprezintă dacă se apelează la modalități noi de dialog, pînă acum neexplorate. Prin intermediul lor, creația acestora poate contribui substanțial la cunoașterea între culturi.

B. Modalitățile de promovare contemporane au resurse nebănuite și în mod cert vor influența societatea, fiind de-a dreptul imprevizibile. Faptul a fost posibil numai datorită existenței noilor tehnologii ale comunicării și vitezei uluitoare cu care acestea se upgradează. Ele facilitează reacții rapide, aproape instantanee.

C. Asimilarea contribuțiilor culturale ale scriitorilor și pătrunderea lor în dialogul SIC, indiferent de epoca în care au trăit și de limba în care au scris, este inculcată în „grilele” postmodernităţii. Vor fi privilegiate acele opere al căror mesaj continuă să ființeze printre interogațiile și răspunsurile ce frămîntă noile generații.

Prin urmare, în absența efectelor (benefice) ale fenomenului mondializării (globalizării), despre care nu toți împărtășim același optimism, experimentul ar fi fost imposibil de realizat, deci sortit eșecului. 


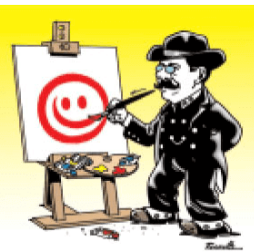

F. A. Ferreira Brazilia

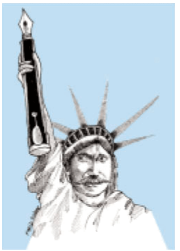

Farid Oidder Maroc

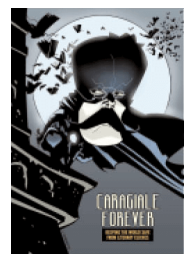

V. Kalvachev

Bulgaria



Michail Neiman Rusia

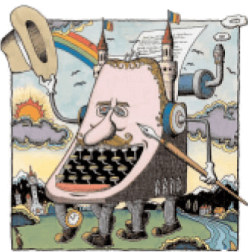

Ken Crane

Japonia



Deano Car S.U.A.

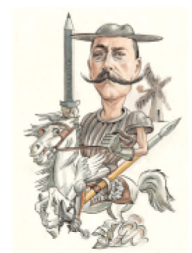

M. Amanbaev

Kazabstan

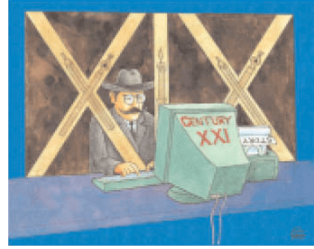

M. Eshonkulov Uzbekistan

Figura 9

\section{Bibliografie}

Arasse, D. (1996). Le détail. Pour une histoire rapprochée de la peinture, Flammarion, coll. Champs arts, Paris. Arnheim. R. (1976). La pensée visuelle, Flammarion, Paris.

Baber, H.E. (2012). Dilemmas of Multiculturalism: An Introduction, în „The Monist”, vol. 95, nr. 1, ian., p. 3-16, Crossref. Bourdieu, P. (1993). The Field of Cultural Production, Columbia University Press, New York.

Brooks, R. L. (2012). Cultural Diversity: It's all about the mainstream, în „The Monist”, vol. 95, nr. 1, ian., p. 17-32, Crossref. Condon, J. C. \& Yousef, F. S. (1975). Introduction to intercultural communication, Bobbs-Merrill Company, New York.

Cuccioletta, D. (2001-2002). Multiculturalism or Transculturalism: Towards a Cosmopolitan Citizenship, în „London Journal of Canadian Studies", vol. 17, Plattsburgh State University of New York, Interdisciplinary Research Group on the Americas, 15 ian.

Drăgănescu, M. (2001). Societatea informațională a cunoașterii. Vectorii societății cunoașterii, în Filip, F. Gh. (ed.), Societatea informațională. Societatea cunoaşterii (concepte, soluții şi strategii pentru România), Academia Română, Bucureşti, p. 43113.

Durand, G. (1992). Les structures anthropologiques de l'imaginaire, Dunod, Paris.

Huntington, S. (1998). The Clash of Civilisations and the Reamking of World Order, Antet, Bucureşti.

Graur A. \& Wald, L. (1977). Scurtă istorie a lingvisticii, Editura Didactică şi Pedagogică, Bucureşti.

Ioniță, N. (2009). O istorie a literaturii române desenată de marii graficieni ai lumii, Editura Muzeul Literaturii Române, București.

Ioniță, N. (2012). I. L. Caragiale - un omagiu planetar, 3 volume, 1500 pagini, Editura Muzeul Literaturii Române Bucureşti.

Lewis, J. (2002). The Cultural Dynamic, „From Culturalism to Transculturalism”, Iowa Journal of Cultural Studies 1 (Spring 2002).

Mitchell, W.J.T. (2009). Iconologie. Image, texte, idéologie, Introduction, Avant-propos des traducteurs, Les Prairies ordinaires, Paris.

Pauzet, A. (2005). Représentations picturales et imaginaire collectif, în „Etudes de Linguistique Appliquée. Revue de didactologie des langues-cultures", vol. 2, nr. 138, p. 137-151.

Slimbach, R. (2005). The Transcultural Journey, în „The Interdisciplinary Journal of Study Abroad”, vol. 11, p. $205-230$.

Toynbee, A.J. (1997). Study over history, Humanitas, Bucureşti.

Simmel, G. (1987). Der Konflikt der modernen Kultur, în Das individuelle Gesetz: Philosophische Exkurse, herausgegeben und eingeleitet von Michael Landmann, Frankfurt a. M., Suhrkamp, p. 148-173.

Vianu, T. (1982). Studii de filozofia culturii, Editura Mihail Eminescu, Bucharest. 